

Annals of DAAAM for 2011 \& Proceedings of the 22nd International DAAAM Symposium, Volume 22, No. 1, ISSN 1726-9679 ISBN 978-3-901509-83-4, Editor B. Katalinic, Published by DAAAM International, Vienna, Austria, EU, 2011 Make Harmony between Technology and Nature, and Your Mind will Fly Free as a Bird Annals \& Proceedings of DAAAM International 2011

\title{
ASSESSMENT METHODS OF DIFFERENT LASER WELDED DENTAL ALLOYS
}

\author{
ARDELEAN, L[avinia] C[osmina]; RECLARU, L[ucien]; BORTUN, C[ristina] M[aria] \& \\ RUSU, L[aura] C[ristina]
}

\begin{abstract}
The aim of this study is to assess the characteristics of laser welding, by different methods such as: scanning electronic microscope observation and metallography. The quality of welding can also be tested by non-invasive methods, which make possible its macro- and microscopic assessment. The alloys assessed are a titanium-based alloy, a standard Au$\mathrm{Pd}$ alloy for the metallo-ceramic technique and a Cr-Co-Mo alloy. The conclusion of the testing is that laser welding is generally mechanically satisfactory.
\end{abstract}

Key words: welding, dental alloys, laser, non-invasive methods, metallography, scanning electronic microscopy

\section{INTRODUCTION}

During the past years, laser welding has been extended to dental technique as it permits the joining of various pieces made of similar or different alloys, which might be difficult with other techniques. (Watanabe et al., 2006). For example, titanium or titanium-alloy pieces, welded pieces used during repair works of partials made of Co-Cr alloys, which permit the preservation of the components of the denture piece which might deteriorate during heating (composites or teeth) by using usual techniques. (Pop et al., 2007) It is equally possible, thanks to this welding method, to weld elements situated in inaccessible places, such as the inner part of an element, splinting extremely small and delicate elements, or splinting of extremely sensitive elements. (Reclaru et al., 2010)

The main advantage of the method is that of cold welding, even on a model.

The quality of laser welded joints of some dental alloys can be evaluated by invasive and non-invasive methods. Some of the invasive methods are: metallographic analysis and microhardness testing and non-destructive methods are: spectrographic and radiographic analyses. (Bortun et al., 2005)



Fig. 1. Laser welding of electronic microcomponents (right) and diamond welded on steel for grinding instruments (left).

\section{MATERIAL AND METHODS}

The alloys assessed by scanning electronic microscope observation and metallography are the titanium-based TA6V4 alloy and a standard $\mathrm{Au}-\mathrm{Pd}$ alloy for the metallo-ceramic technique.
The TA6V4 alloy is a titanium-based alloy containing $6 \%$ aluminum and $4 \%$ vanadium, mainly used in manufacturing prefabricated pieces for implantology. As the pseudo-binary phase diagram shows, at room temperature the alloy is biphased Ti $\alpha+$ Ti $\beta$, with a slight phase percentage for Ti $\beta$. The existence of the two phases Ti $\alpha$ and Ti $\beta$, at room temperature, makes possible the creation of an alloy with a high mechanical resistance, due to the mutual interaction of the two phases. The alloy has an elasticity limit of $875 \mathrm{MPa}$.

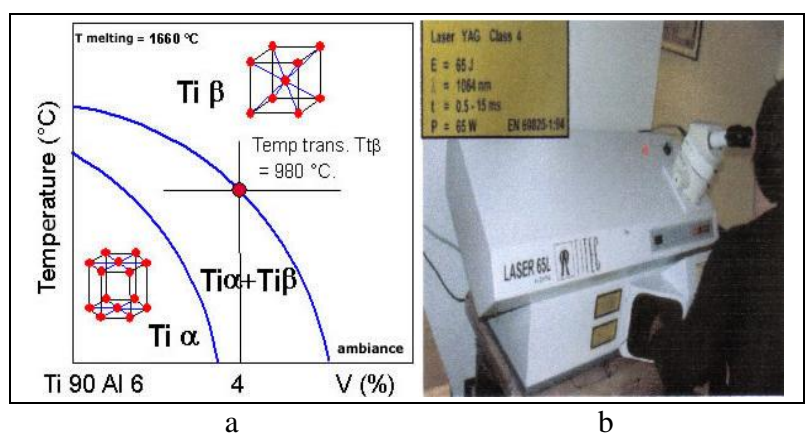

Fig. 2. a) Schematic pseudo-binary phase diagram of TA6V4. (right), b) LASER $65 \mathrm{~L}$ - TITEC with welding parameters (left)

During heating the Ti $\alpha$ turns into Ti $\beta$ at approximately $980^{\circ} \mathrm{C}$. During fast cooling, the $\mathrm{Ti} \beta$ phase undergoes a socalled martensitic transformation forming a complex lamellar structure inducing significantly altered mechanical properties. These mechanical properties will be recovered by a lowtemperature thermal treatment.

The Au-Pd alloy used in the the metallo-ceramic technique, welded by laser technique, is a standard alloy, containing $51.2 \% \mathrm{Au}, 38.6 \% \mathrm{Pd}$, indium, gallium and ruthenium as additional elements.

The third alloy was the $\mathrm{C}$ alloy, which is currently used by the authors in making metallic components of partial dentures. Plates of this Cr-Co-Mo alloy were cast, their thickness varying from $0.4 \mathrm{~mm}$ to $0.9 \mathrm{~mm}$, and they were welded with the laboratory Nd-Yag laser: LASER $65 \mathrm{~L}$ - TITEC.

\section{RESULTS}

Metallurgic analysis of the TA6V4 alloy sample, by metallography and scanning electronic microscope observation, after a single impulse laser impact, reveals the following: after cooling there is a melting area (MA), a thermally-affected area (TAA) and an area corresponding to the base alloy (BAA). The MA is mainly formed of Ti $\beta$ turned by martensitic transformation into Ti $\alpha$ '. The TAA is mainly composed of two sublayers developed near the MA, formed of a Ti' structure and, deeper down, of a complex $\operatorname{Ti} \alpha+\operatorname{Ti} \beta+$ Ti $\alpha$ structure. The BAA consists of the Ti $\alpha+\operatorname{Ti} \beta$ structure. The elasticity limit during high temperatures decreases and the resistance to wear is rather unaffected by laser welding. 


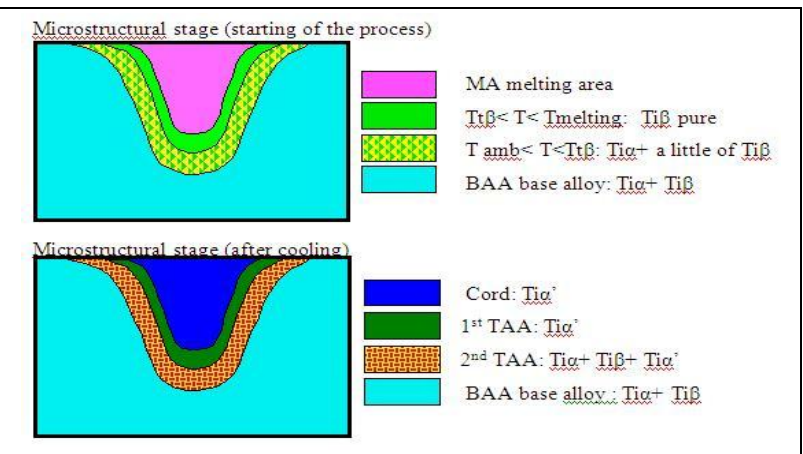

Fig. 4. Schematic description of the cord during welding

For the $\mathrm{Au}-\mathrm{Pd}$ alloy used in the metallo-ceramic technique, the figures show the successive impacts leading to the welding of the two pieces. Like in the case of a titaniumbased alloy, there is a very perturbed TAA and a lamellar structure of the melting area.

For the $\mathrm{C}$ alloy, the welding area, dyed in yellow, shows no fissures in the immediate vicinity of the welding - in the TAA - because the laser is used at very low temperatures and there are no contractions in the analyzed material. However, Xrays show radio-transparence in the fusion area, which indicates that the fusion is a superficial one and does not cover the entire thickness of the fused alloy. Although $\mathrm{C}$ alloy plates used are not very thick, welding does not cover the whole depth. This results in the fragility of the welding.



Fig. 5. SEM observation of the TA6V4 cord sample after a single impulse laser impact

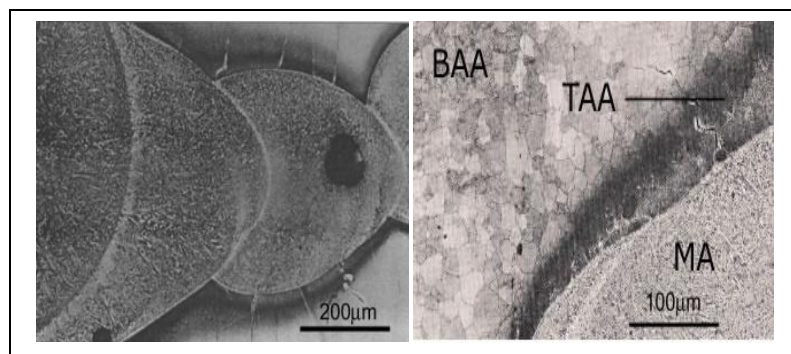

Fig. 6. Welded area: SEM (right) and metallography (left)

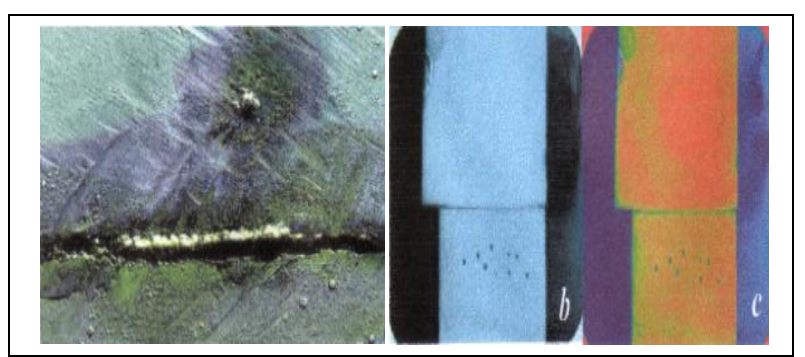

Fig. 7. Assessment of the welded area: a. basic fuchsin dyestaining; b. X-ray; c. pseudo-chromatization

\section{DISCUSSION}

In the case of TA6V4 alloy it is important to observe that the cooling speed plays an important role on its mechanical characteristics due to its influence on the phase transformation structures into a solid state. The elasticity limit during high temperatures decreases and the resistance to wear is rather unaffected by laser welding due to the fact that the cord has no porosities or other defects (cracks, snaps).

In case of the $\mathrm{Au}-\mathrm{Pd}$ alloy for the metallo-ceramic technique, it appears that the resistance to fracture of the laser welded area is higher than in the case of brazing. On the other hand, the resistance to wear of laser welding is lower than that of brazing.

Laser welding is suitable to weld titanium and its alloys because they have higher rates of laser beam absorption and lower thermal conductivity than other dental casting alloys, such as gold alloys; however, due to the strong reactivity of molten titanium with oxygen, the incorporation of oxygen during laser welding may affect the joint strength. (Susz et al., 2011)

Concerning the $\mathrm{C}$ alloy, the main advantage of the method is that of cold welding, even on a model. Plate assessment shows that the fusion area - laser welding - seems microscopically fragile, being easily breakable. X-rays do not show fissures in the fusion area or in the thickness of the basic material.

\section{CONCLUSIONS}

As a rule, laser welding is mechanically satisfactory. (Szuhanek, 2010) In order to avoid problems, initially, both parts of the joined piece should be subjected to low level energy impacts, followed by greater energy for filling. (Baba\& Watanabe, 2005) The success of the welding procedure also depends on the operator's dexterity and the choice of the welding parameters. (Achebo, 2010)

Further research will be carried out using more different types of dental alloys, in order to asses and compare their behavior when laser welding is performed and determine the proper parameters for each type of dental alloy.

\section{REFERENCES}

Achebo, J. (2010). Optimizing Stoichiometric Welding Fluxes Using Nested Random Model, Chapter 36 in DAAAM International Scientific Book 2010, B. Katalinic (Ed.), pp. 377-394, Published by DAAAM International, ISBN 978-3901509-74-2, ISSN 1726-9687, Vienna, Austria

Baba N. \& Watanabe I. (2005). Penetration depth into dental casting alloys by Nd:YAG laser. Journal of Biomedical Materials Research Part B: Applied Biomaterials, Vol. 72, No. 1, 2005, pp. 64-68, ISSN 1552-4973

Bortun C.; Mitelea I.; Milos L.; et al. (2005). Analysis of laser welded joints on "C" alloy in the removable partial dentures technology. European Cells and Materials, Vol. 10, Suppl. 1, 2005, pp.31, ISSN 1473-2263.

Pop D.; Negrutiu M.; Sinescu C.; et al. (2007). Different Types of Laser Welding in Dental Technology. Timisoara Medical Journal, Vol. 57, No. 2-3, 2007, pp. 184-186, ISSN 1583$526 \mathrm{X}$

Reclaru L.; Susz C.; Ardelean L. (2010). Laser beam welding. Timisoara Medical Journal, Vol.60, No.1, 2010, pp. 86-90, ISSN 1583-526X

Susz C.; Reclaru L.; Ardelean L.; Ghiban B. \& Rusu L. (2011). Aliaje dentare, Ed. Victor Babes, ISBN 978-606-8054-32-2, Timisoara,Romania

Szuhanek, C. (2010). Mechanical Properties of Welded Orthodontic Metal Appliances, Chapter 24 in DAAAM International Scientific Book 2010, B. Katalinic (Ed.), pp. 237-244, Published by DAAAM International, ISBN 978-3901509-74-2, ISSN 1726-9687, Vienna, Austria

Watanabe I. ; Baba N. ; Chang J. ; et al. (2006). Nd:YAG laser penetration into cast titanium and gold alloy with different surface preparations. Journal of Oral Rehabilitation, Vol. 33, No. 6, 2006, pp. 443-446, ISSN 0305-182X 